\title{
Correlation of mission type to cyclic loading as a basis for agile military aircraft asset management
}

\author{
Jeffrey Newcamp*, W.J.C. Verhagen, Richard Curran \\ Delft University of Technology, Faculty of Aerospace, Kluyverweg 1, 2629 HS Delft, Netherlands
}

Military attack aircraft are susceptible to the harmful effects of widespread fatigue damage caused by cyclic loading of structural components, which leads to airframe retirement. Modern structural health monitoring techniques use a multitude of sensors and high data collection rates. Some legacy airframes, which are most susceptible to fatigue damage due to their age, possess a counting accelerometer technology with few sensors and low data capture rates. The data provided by these 40-year old devices are crucial to understanding fleet health and can be used to extend structural lifetime for aging aircraft. Existing literature has addressed counting accelerometer usefulness, but a profound three-decade gap in research has led to a chasm between the current wealth of available data and tool development for utilizing those data. This research uses 11 years of A-10 Thunderbolt II counting accelerometer data to prove that mission type, mission duration and aircraft type correlate to aircraft loading patterns. It is shown that a mission type model can therefore influence fleet management strategies and the structural lifetime extension for aging aircraft.

Keywords: Military Aircraft, Mission Type, Structural Lifetime, Accelerometer

\section{Introduction}

Mission type usage for military attack aircraft varies widely and the particular utilization pattern is important for determining an airframe's lifetime. As an aircraft fleet ages, the initial lifetime estimate must be updated to reflect usage patterns. These calculations are especially important in a fiscal climate where air forces are retaining aircraft longer than initially projected. For example, the United States Air Force (USAF) employs a fleet averaging 26 years old, with an average age of 21 years for the attack/fighter aircraft subgroup [1]. A 2012 study concluded that the USAF fleet is the oldest it has ever been with no strategy in place to reverse the trend [2], [3]. The problem of aging aircraft is not new and accordingly, the Department of Defense's (DoD) policy has evolved through time. MIL-HDBK-1530 and the USAF Policy Directive 63-10 are two examples of how serious the DoD has taken aging aircraft issues [4], [5]. The Aircraft Structural Integrity Program (ASIP) has implemented inspections and enhanced monitoring to decrease the effects of aircraft aging [6], [7]. While there is a strong emphasis on monitoring for structural deterioration, there is much less emphasis on how mission type impacts loading.

For this research on aircraft loading, the A-10 Thunderbolt II was chosen as the case study aircraft. It is an aging aircraft, first reaching initial operating capability in 1977 [8]. The A-10 was built by Fairchild Republic to fill the close air support role for the USAF. It is a single-seat, twin-turbofan engine aircraft with a low wing, low-tail configuration possessing advanced survivability characteristics [9]. The structure is mostly aluminum with the primary exception of titanium armor shielding the cockpit from ground fire. Base weight is 28,000 pounds and normal operating weight is 35,000 to 50,000 pounds. Though categorized as an attack aircraft, zero-g or negative-g maneuvers greater than 10 seconds are forbidden. The maximum airspeed is 450 knots indicated airspeed, or Mach 0.75, whichever is lower. At a nominal weight of 30,000 pounds at sea level, the normal load factor $\left(\mathrm{N}_{\mathrm{z}}\right)$ limits are $+7.3 \mathrm{~g} /-3.0 \mathrm{~g}$. The A-10 possesses a basic structural health monitoring system known as a counting accelerometer governed by a now rescinded military specification [10], [11].

The A-10 System Program Office of the USAF provided data from its Aircraft Data Acquisition and Distribution System (ADADS) for this study. Each A-10 has a counting accelerometer unit that records counts in discrete bins each representing an $\mathrm{N}_{\mathrm{z}}$ loading $(0.3 \mathrm{~g}, 2.5 \mathrm{~g}, 3 \mathrm{~g}, 4 \mathrm{~g}, 5.5 \mathrm{~g}$ and $7 \mathrm{~g})$. These counts are unidirectional, meaning that an aircraft maneuver to $4.8 \mathrm{~g}$ would accrue one count in each of the $2.5 \mathrm{~g}, 3 \mathrm{~g}$ and $4 \mathrm{~g}$ bins. The system does not provide a time-history nor does it provide aircraft weight information. For each mission, the counting accelerometer data were transcribed by maintenance ground crews onto an Air Force Technical Order (AFTO) form 278. The mission pilot then hand-carried the form into maintenance debrief and handed off the data to a support person who inputted the data into a digital storage service managed by the Oklahoma City Air Logistics Complex (OC-ALC). The ASIP manager is responsible for analyzing loading pattern data and for implementing fleet-wide changes. This data collection process is shown in Fig. 1.

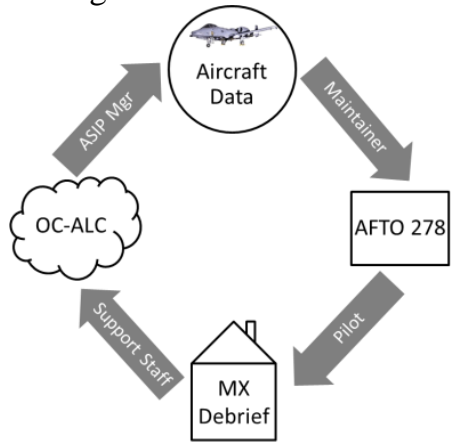

Fig. 1. Aircraft Data Acquisition and Distribution System data flow.

\footnotetext{
* Corresponding author.

E-mail address: j.m.newcamp@tudelft.nl
} 
This research analyzed two important hypotheses about aircraft loading. The first was that the type of flying mission impacts the loading pattern experienced by a military attack aircraft. Second, some mission types account for greater loading accumulation. These two hypotheses are essential first steps for future phases of this effort which aim to develop a fleet optimization model for assigning military aircraft to operational locations while maximizing aircraft availability and extending useful life.

\subsection{Theoretical Context}

The A-10's counting accelerometer technology originated in the 1950s so there exists a plethora of related work in the 1950s, 1960s and 1970s but a dearth in the 1980s through present. Accordingly, the theory and methodologies developed at the outset of counting accelerometer usage have not been updated since the 1970s. The seminal work in counting accelerometers was conducted by Taylor who discussed counting accelerometer technology from a design perspective in 1954 [12]. Gray's work applied counting accelerometer systems to individual aircraft tracking for fatigue crack growth prediction [13]. Lambert's work in 1973 applied tracking data to life predictions and fleet optimization [14]. He suggested fleet basing optimization as a way to extend aircraft lifetimes because his work showed a theoretical relationship between aircraft stress and sortie pattern combination. Lambert did not propose ways to optimize fleets or basing and his theoretical calculations used generic data, not collected data.

De Jonge's 1989 work using counting accelerometer data was among the most recent. He studied Royal Netherlands Air Force F-104G operational data and used a Weibull distribution to represent load factor cumulative occurrence distributions, which were different for reconnaissance, strike and air defense mission categories [15]. De Jonge's study followed 15 counting accelerometer instrumentation kits that were installed on various aircraft over a 10-year period. His data comprised 9,500 flights but did not have the tail-number specificity that the A-10 data in this study possesses.

Aging aircraft operators are responding to aging aircraft fleet problems through enhanced structural health monitoring, as discussed by Albert et al, Connor et al, Maley et al and at length in Staszewski et al [16], [17], [18], [19]. Boyd wrote that the greatest impact on the aging process comes from postmanufacturing decisions [20]. This implies that combining structural health monitoring with usage decisions can impact fleet health. Unfortunately, current data collection is not uniform across aircraft fleets. Even within one mission design series, there exist multiple generations of flight data recorder technology possessing incremental capabilities. Therefore, historical data take many forms, making it difficult to conduct both longitudinal and horizontal studies. This research evaluated existing structural health monitoring data to draw correlations that are useful to different aircraft types.

The author recognizes the inferiority of a counting accelerometer system, as outlined by De Jonge, but the author understands the importance of developing tools to use these data [21]. The USAF has decades of counting accelerometer data that can be used for lifetime optimization but few established tools for analysis. Despite the failings of the data type, there still exists opportunity to use the data.
The remainder of this paper will address the two hypotheses listed in this introduction. This unprecedentedly large analysis of the entire A-10 fleet will show a new look at how mission type impacts aircraft loading patterns. The next section discusses the methodology used to analyze the data provided by the USAF, including the practice of data reduction and the established norms for analyzing counting accelerometer data. Then, the results section presents a thorough treatment of counting accelerometer data both in aggregate form and in population subsets. The relationship between g-count occurrences and mission type is analyzed, exponential usage models for each mission type are presented and an analysis of important findings is presented. Data verification then shows the relationship between this study's data and existing studies. Lastly, the conclusions section summarizes the findings from this study.

\section{Methodology}

\subsection{Data Reduction}

The dataset from the USAF ADADS database contained 456,847 unique entries spanning from January 2002 to August 2015. The counting accelerometer data capture rates were low during 2002 and 2003 so data from those years were removed from the dataset. Only half of the collection year for 2015 had occurred at the start of this study, so 2015 data were excluded. These exclusions resulted in 407,634 viable sorties. Because the data collection was subject to many failure modes (missing data, human error and accelerometer malfunctions), there resulted 278,678 useful entries after multiple filtering algorithms were applied. These algorithms removed clear errors: sortie durations $d$ outside the reasonable range of $0.3<d<15$ hours, sorties firing more rounds than capacity allows and sorties with counting accelerometer failures indicated by discontinuities. Further reduction of the population was undertaken to remove eight infrequently flown mission types. Fig. 2 illustrates the data reduction process.

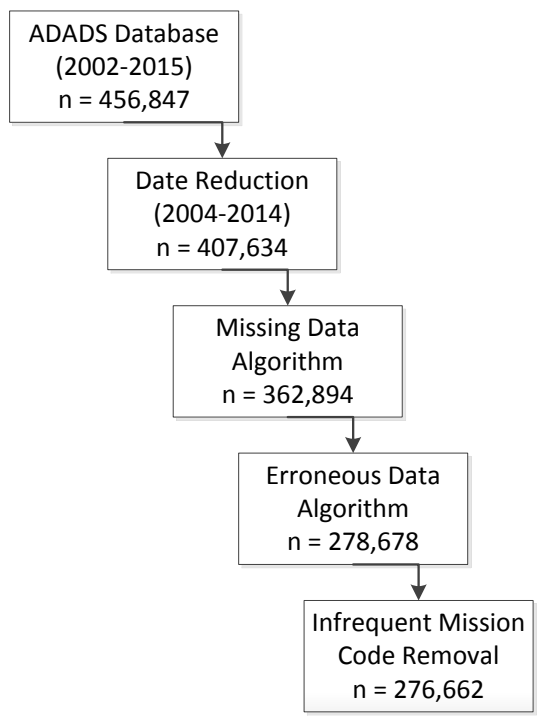

Fig. 2. Data reduction process steps.

Descriptive statistics of the full dataset and the edited dataset show that the reduction steps did not skew the data. The means 
for flight duration and number of rounds fired only show minor shifts between the full dataset and the edited dataset $(0.40 \%$ and $4.42 \%$ losses, respectively). These outcomes are reasonable. Only six of the original 365 tail numbers were removed and those six aircraft only represented seven missions in the original 2002-2015 dataset.

Because this research relies on understanding fleet usage, losing a portion of the dataset would have resulted in an underestimation of yearly usage. To correct for this the associated number of sorties and mission types from the full dataset were reserved for analysis alongside the edited dataset. The erroneous counting accelerometer data were not replaced or corrected.

\subsection{Modeling the Usage Spectrum}

Two assumptions were required during the modeling effort. The first was that data collected for mission types are representative of those missions. For example, if a pilot states that his mission was Close Air Support (CAS), then that pilot flew CAS for the majority of the mission. The second assumption was that the data contained in the study population from 2004-2014 is representative of the entire lifetime for the aircraft analyzed. Since there were not significant differences found between the years in the study, this assumption is reasonable.

The ADADS database accepts 18 unique mission codes, however the top 10 mission codes represented $99.33 \%$ of all missions and the remaining eight codes were antiquated. Table 1 shows the 10 currently used mission codes along with the percentage of missions each represented in the dataset. One can see that the six most frequent mission codes account for $96.33 \%$ of all missions. Codes SAR, FAC, NAV and FCF were still included in the model despite their low representation because of their relevance to overall A-10 operations and loading spectra. For example, the Functional Check Flight (FCF) code only accounts for $0.58 \%$ of all A-10 missions, but an FCF is a fullenvelope check of the aircraft and greatly contributes to the width of the loading spectrum envelope.

Table 1

Mission types retained for analysis.

\begin{tabular}{crrr}
\hline $\begin{array}{c}\text { Mission } \\
\text { Code }\end{array}$ & $\begin{array}{c}\text { \% of } \\
\text { Dataset }\end{array}$ & $\begin{array}{r}\text { Cumulative } \\
\text { \% }\end{array}$ & $\begin{array}{r}\text { Median Missions } \\
\text { In Fleet (1 yr) }\end{array}$ \\
\hline CAS & 48.95 & 48.95 & 17,966 \\
SAT & 14.00 & 62.95 & 5,182 \\
OTH & 13.83 & 76.78 & 5,250 \\
BFM & 7.26 & 84.04 & 2,543 \\
SA & 7.10 & 91.14 & 2,866 \\
AR & 5.19 & 96.33 & 1,472 \\
SAR & 1.00 & 97.33 & 351 \\
FAC & 0.74 & 98.07 & 254 \\
NAV & 0.68 & 98.75 & 203 \\
FCF & 0.58 & 99.33 & 211 \\
\hline Sum: & 99.33 & & 36,298 \\
\hline
\end{tabular}

A typical year for the A-10 fleet flies this mix of missions. It is from these data that one can understand the demands placed on the fleet. To simplify the usage data to a typical year, the medians of each mission code shown in Table 1 were calculated over the 11-year population. Fleet-wide, the median number of missions per year was 36,298. This number is subject to a variety of influences: political changes, budgetary climate and combat needs.

\subsection{Data Analysis}

The edited database contained these factors: aircraft tail number, six levels of counting accelerometer data, an elapsed time indicator, mission type, base of assignment, rounds fired, date, flight duration and cumulative flight hours. Principal component analysis showed that mission type, mission duration, rounds fired and base of assignment had high eigenvalues and were the factors that impacted counting accelerometer occurrences and therefore explained the variance in the dataset. Each of these factors except rounds fired is discussed in this paper.

The established approach for analyzing aging aircraft counting accelerometer data is discussed by both Denyer and Gray [22], [13]. The calculation of normal load factor occurrences per 1,000 flight hours is used as the standard for comparison with historical studies (Equation 1). Normal load factor, $N_{z_{j}}$ represents the counting accelerometer bins where $j=\{0.3,2.5,3,4,5.5,7\}$.

$$
C=\frac{\sum_{1}^{n} N_{z_{j}} \text { Occurrences }}{\sum_{1}^{n} \text { Flight Hours }} \times 1,000
$$

Aircraft within one mission design series experience a range of loads, but that variability can be considered stochastic. De Jonge's work with counting accelerometers acknowledges this, allowing the methodological use of Equation 1 for comparisons between different mission types [21]. Holpp and Landy also followed this approach using generic, DoD fighter data to assess aircraft loading spectra [23]. They showed counting accelerometer cumulative occurrence plots from a government study that highlighted differences between air-to-air, air-to-ground and loiter mission type categories. Holpp and Landy did not analyze the differences between mission types nor did they assess the reasons for the differences because their objective was to develop an overarching usage spectrum. De Jonge's later work on fighter aircraft shows a difference in load experience for different mission types [15]. In this approach, he reduces counting accelerometer data to a singular parameter per flight, labeled the load severity factor.

\section{Results}

To address the first hypothesis stating that the type of mission impacts the loading pattern, it must be shown that there exists a measurable difference in counting accelerometer occurrences for each mission type. This will be shown through the distillation of the dataset into mission type subgroups with a subsequent between-subjects treatment using ANOVA. Then to address the second hypothesis, that some mission types account for greater loading accumulation, the mission type subgroup data are parsed. Then their exponential decay model coefficients are compared. Lastly, bivariate correlation and the Pearson productmoment correlation coefficient are used to show the relationship between flight hours and g-count occurrences to demonstrate 
that the established relationships have a positive correlation with increasing time.

\subsection{Loading Environment}

To understand the loading environment differences between missions, it is critical to first establish the loading environment for an individual sortie. The median yearly loading accumulations for the fleet are shown in Table 2. The median g-count occurrences per flying hour represent the distillation of the population data into a tangible cost for each hour an A-10 flies. For example, an A-10 will accumulate the g-count occurrences shown in Table 2 in a 2.26-hour sortie, which is the average sortie duration during the data collection period. The A-10 fleet accumulated 748,812 counts on its $3 \mathrm{~g}$ counters in a median year. Any candidate tail number accumulated 9 counts (integer scale) on the $3 \mathrm{~g}$ counter in one flight hour. For the average A-10 sortie duration of 2.26 hours, a candidate aircraft would receive 20 counts on its $3 \mathrm{~g}$ counter. This is the real structural loading cost of one hour of flight.

Table 2

Distribution of g-counts.

\begin{tabular}{crrr}
\hline $\begin{array}{c}\text { Counting } \\
\text { Accelerometer }\end{array}$ & $\begin{array}{r}\text { Median } \\
\text { Yearly } \\
\text { g-Counts }\end{array}$ & $\begin{array}{r}\text { Mean g- } \\
\text { Counts Per } \\
\text { Flight Hr }\end{array}$ & $\begin{array}{r}\text { Mean g- } \\
\text { Counts Per } \\
\text { Avg Sortie }\end{array}$ \\
\hline $0.3 \mathrm{~g}$ & 194,472 & 2.31 & 5.22 \\
$2.5 \mathrm{~g}$ & $1,267,447$ & 15.42 & 34.85 \\
$3 \mathrm{~g}$ & 748,812 & 9.21 & 20.81 \\
$4 \mathrm{~g}$ & 298,941 & 3.62 & 8.18 \\
$5.5 \mathrm{~g}$ & 32,078 & 0.42 & 0.95 \\
$7 \mathrm{~g}$ & 2,166 & 0.03 & 0.07 \\
\hline
\end{tabular}

These medians and means are powerful tools for fleet managers. Knowing how much loading accumulation occurs in a typical flight hour can help managers predict useful lives for their fleets. Fig. 3 is a box plot of the counting accelerometer data, showing the means, $25^{\text {th }}$ and $75^{\text {th }}$ percentiles as well as outliers. The boxplot whiskers are set to 2.7 standard deviations, so all data beyond them are shown as individual datum points. The box plot shows the relationship between counts on each counting accelerometer for a typical flying hour.

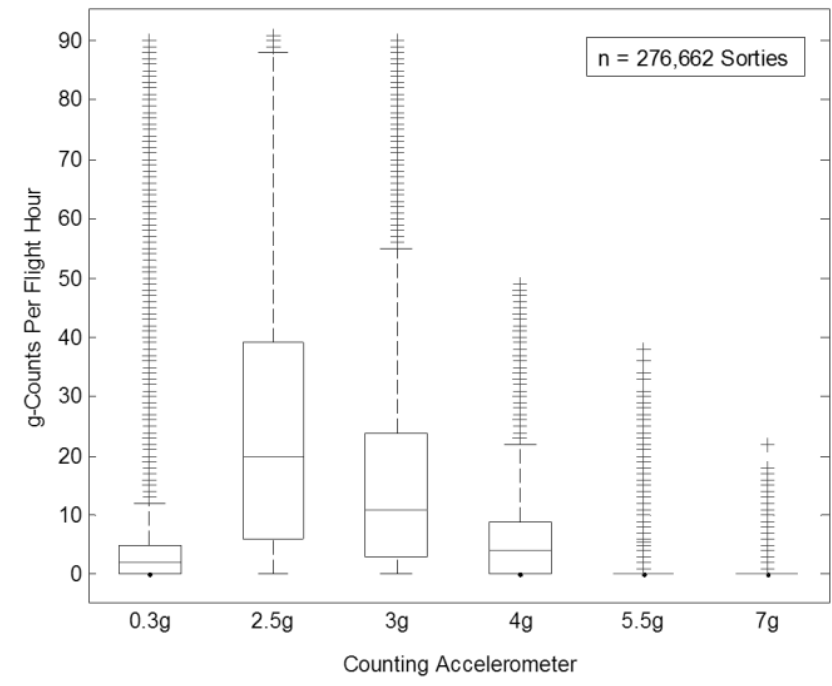

Fig. 3. Box plot of g-counts per flight hour.
Understanding the loading spectrum for a typical year and a typical flying hour are important, but it is essential to know how each mission code affects the loading patterns. Each mission code was isolated in the population to determine its contribution to loading patterns. The g-counts per flight hour for select mission codes are summarized in Fig. 4. Surface Attack (SA), Functional Check Flight (FCF) and Navigation (NAV) were chosen for inclusion because they represent a broad range of the mission type subgroups, thus emphasizing the variability. Because the counting accelerometers are discrete, not continuous, connecting lines were merely added for clarity of presentation.

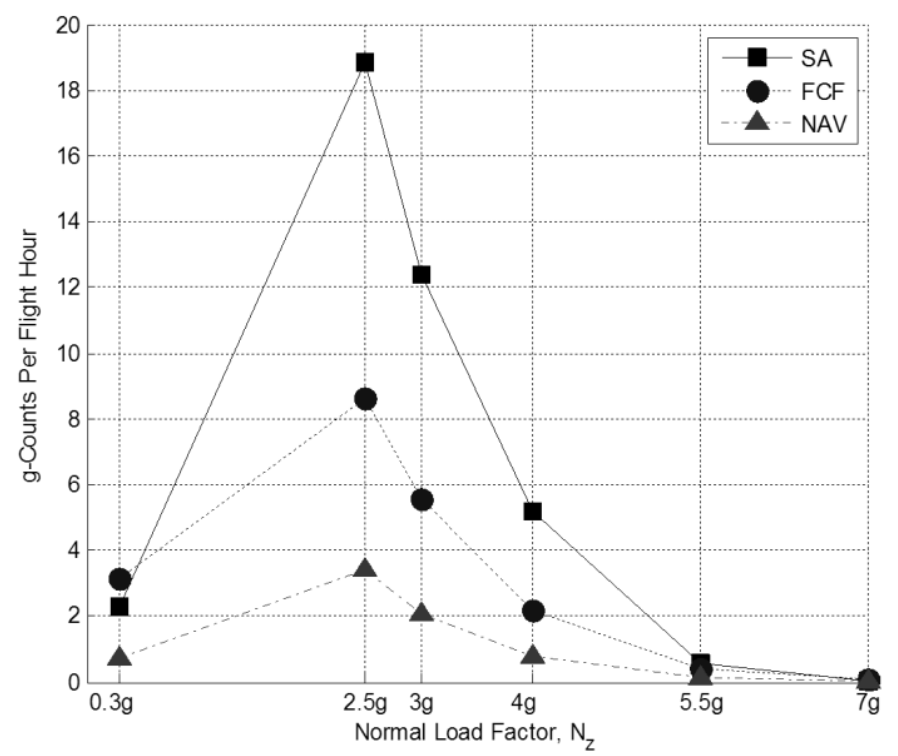

Fig. 4. Loading pattern per flight hour for mission types.

These data answer several important questions. First, the type of mission impacts the loading pattern experienced by the aircraft. The types of missions flown impact how many g-count occurrences are accumulated on the fleet. The stratification in the data is more visible at the lower g-levels with less variance at the $5.5 \mathrm{~g}$ and $7 \mathrm{~g}$ levels. In the full dataset not shown here, some mission types stand out compared to the others. Close Air Support (CAS) and Surface Attack Tactics (SAT) both have greater counts per flight hour than the other mission types. Other $(\mathrm{OTH})$ is found close to the median at each bin. OTH is the catch-all mission code when a pilot felt that he did not predominantly fly one of the other mission codes, so this code is less valuable and serves as a proxy median. Consequently, fleet managers cannot use the data provided by OTH to devise fleet optimization algorithms.

Applying Equation 1 to these data allows for comparison to legacy aircraft and across time. The cumulative normal load factor occurrences per 1,000 flight hours for the same selected mission types are shown in Fig. 5. Connecting lines were again added for clarity of presentation. The logarithmic ordinate best represents the differences between mission type usage severity across the full spectrum of recorded normal load factors and confirms the result that mission type impacts the loading pattern. 


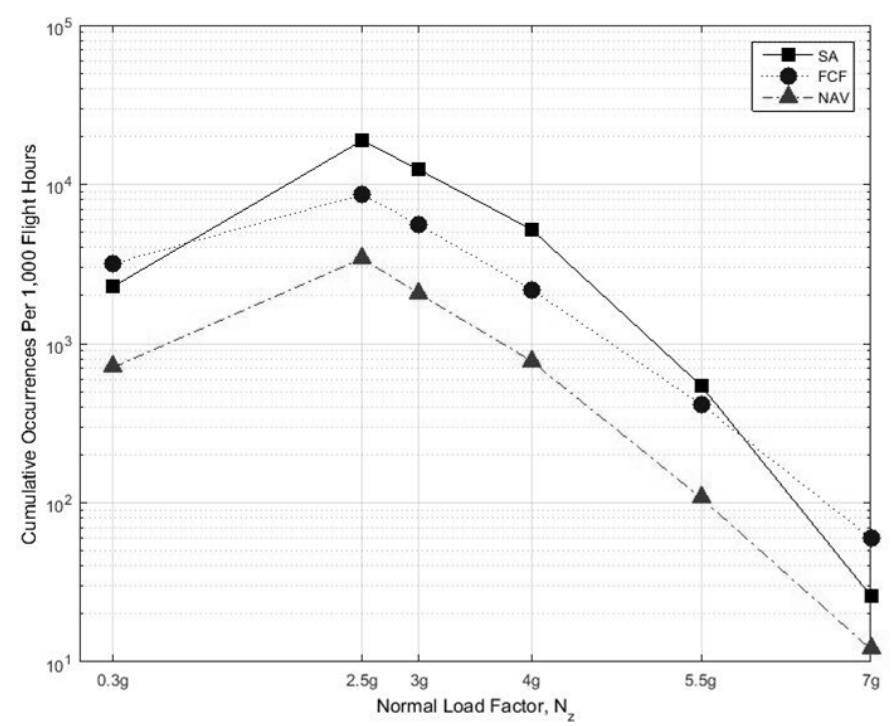

Fig. 5. Usage severity shown for select mission types.

The underlying data used for Fig. 4 and Fig. 5 showed that the SAT and OTH g-count loading patterns are similarly shaped. An ANOVA to detect between-subjects effects shows significance for four of the six normal load factors, shown in Table 3. Fleet managers cannot be certain that the SAT and OTH $5.5 \mathrm{~g}$ and $7 \mathrm{~g}$ trends are distinct due to their high $\mathrm{p}$-values.

Table 3

SAT-OTH ANOVA comparison.

\begin{tabular}{crl}
\hline $\begin{array}{c}\text { Counting } \\
\text { Accelerometer }\end{array}$ & f-Statistic & p-Value \\
\hline $0.3 \mathrm{~g}$ & 24.603 & 0.000 \\
$2.5 \mathrm{~g}$ & 15.222 & 0.000 \\
$3 \mathrm{~g}$ & 36.924 & 0.000 \\
$4 \mathrm{~g}$ & 326.662 & 0.000 \\
$5.5 \mathrm{~g}$ & 0.750 & 0.386 \\
$7 \mathrm{~g}$ & 0.140 & 0.708 \\
\hline
\end{tabular}

The counting accelerometers were analyzed for variance using an ANOVA. Table 4 shows that the variance present within the counting accelerometer subgroups $(0.3 \mathrm{~g}, 2.5 \mathrm{~g}, 3 \mathrm{~g}, 4 \mathrm{~g}$, $5.5 \mathrm{~g}$ and $7 \mathrm{~g}$ ) are significant and should therefore be treated as different in further analyses.

Table 4

Summary of mission code ANOVA.

\begin{tabular}{crl}
\hline $\begin{array}{c}\text { Counting } \\
\text { Accelerometer }\end{array}$ & f-Statistic & p-Value \\
\hline $0.3 \mathrm{~g}$ & 364.988 & 0.000 \\
$2.5 \mathrm{~g}$ & 1609.144 & 0.000 \\
$3 \mathrm{~g}$ & 2063.013 & 0.000 \\
$4 \mathrm{~g}$ & 2373.582 & 0.000 \\
$5.5 \mathrm{~g}$ & 285.735 & 0.000 \\
$7 \mathrm{~g}$ & 26.870 & 0.000 \\
\hline
\end{tabular}

\subsection{Mission Evaluation}

To show the correlation of loading pattern to mission type, it was required to map each mission code to the counting accelerometer data. Counter occurrences per sortie were evaluated, as were the percentages of counter occurrences with respect to the sum for each mission code. Both of these approaches presented factual but incomplete results because neither depicted usage in terms useful to aircraft managers. Since flight hours are the basic unit of aircraft usage, counter occurrences per flight hour best represented the loading patterns. All values higher than the mean in the counter subgroups (columns) are bolded.

Table 5

Counting accelerometer occurrences per hour for each mission type.

\begin{tabular}{ccrrrrr}
\hline $\begin{array}{c}\text { Mission } \\
\text { Code }\end{array}$ & $\mathbf{0 . 3 g}$ & $\mathbf{2 . 5 g}$ & $\mathbf{3 g}$ & $\mathbf{4 g}$ & $\mathbf{5 . 5 g}$ & $\mathbf{7 g}$ \\
\hline SAT & $\mathbf{2 . 2 8}$ & $\mathbf{1 5 . 9 0}$ & $\mathbf{9 . 8 3}$ & $\mathbf{3 . 6 8}$ & $\mathbf{0 . 3 6}$ & 0.02 \\
AR & $\mathbf{2 . 5 0}$ & $\mathbf{1 3 . 7 6}$ & $\mathbf{8 . 6 7}$ & $\mathbf{3 . 4 4}$ & 0.32 & 0.02 \\
BFM & $\mathbf{3 . 2 1}$ & $\mathbf{1 5 . 9 7}$ & $\mathbf{1 0 . 8 7}$ & $\mathbf{4 . 8 6}$ & $\mathbf{0 . 4 8}$ & $\mathbf{0 . 0 4}$ \\
CAS & 1.31 & 8.26 & 4.84 & 1.82 & 0.19 & 0.01 \\
FAC & 1.50 & 9.93 & 5.65 & 2.08 & 0.23 & 0.01 \\
FCF & $\mathbf{3 . 1 7}$ & 8.65 & 5.58 & 2.18 & $\mathbf{0 . 4 1}$ & $\mathbf{0 . 0 6}$ \\
NAV & 0.71 & 3.42 & 2.06 & 0.77 & 0.11 & 0.01 \\
OTH & $\mathbf{2 . 2 4}$ & $\mathbf{1 4 . 3 7}$ & $\mathbf{9 . 4 3}$ & $\mathbf{3 . 8 6}$ & $\mathbf{0 . 3 3}$ & 0.02 \\
SA & $\mathbf{2 . 2 8}$ & $\mathbf{1 8 . 8 6}$ & $\mathbf{1 2 . 3 7}$ & $\mathbf{5 . 2 0}$ & $\mathbf{0 . 5 4}$ & $\mathbf{0 . 0 3}$ \\
SAR & 1.62 & 12.02 & 6.65 & 1.95 & 0.18 & 0.01 \\
\hline \multicolumn{7}{c}{ Bolded values are above the column mean. } \\
\hline \multicolumn{7}{c}{}
\end{tabular}

The data in Table 5 were transformed to cumulative occurrences per 1,000 flight hours for each counting accelerometer. These data are shown graphically in Fig. 6, where the curve fits are all one-term exponential distributions calculated by Equation 2. Exponential fits were expected because each positive, lesser accelerometer must serially receive a count to register a higher count during a maneuver from $1 \mathrm{~g}$. The $0.3 \mathrm{~g}$ counting accelerometer was masked from this data representation because data between the $0.3 \mathrm{~g}$ and $2.5 \mathrm{~g}$ counters are significantly impacted by the asymptotic nature of the function near $1 \mathrm{~g}$. The value $x$ represents the normal load factor and $a$ and $b$ are coefficient terms. All values of $b$ are negative resulting in exponential decay for increasing load factor. Table 6 shows the coefficients used to build each exponential model.

$$
f(x)=a e^{b x}
$$

The number of occurrences of a particular normal load factor may now be calculated. Then algebraic manipulation yields Equation 3 where the value $y$ represents the number of occurrences per 1,000 flight hours of a normal load factor, $x$. The values $a$ and $b$ are both coefficients.

$$
x=\frac{\ln \left(\frac{y}{a}\right)}{b}
$$

These equations and the exponential models show the differences in loading accumulation for each of the ten mission 
types. The limitation to this approach is that the counting accelerometers are discrete. Continuous data from a digital data recorder could reveal more information about the occurrences experienced at all load factors. Thus, these exponential fits assume exponential behavior between counting accelerometers.
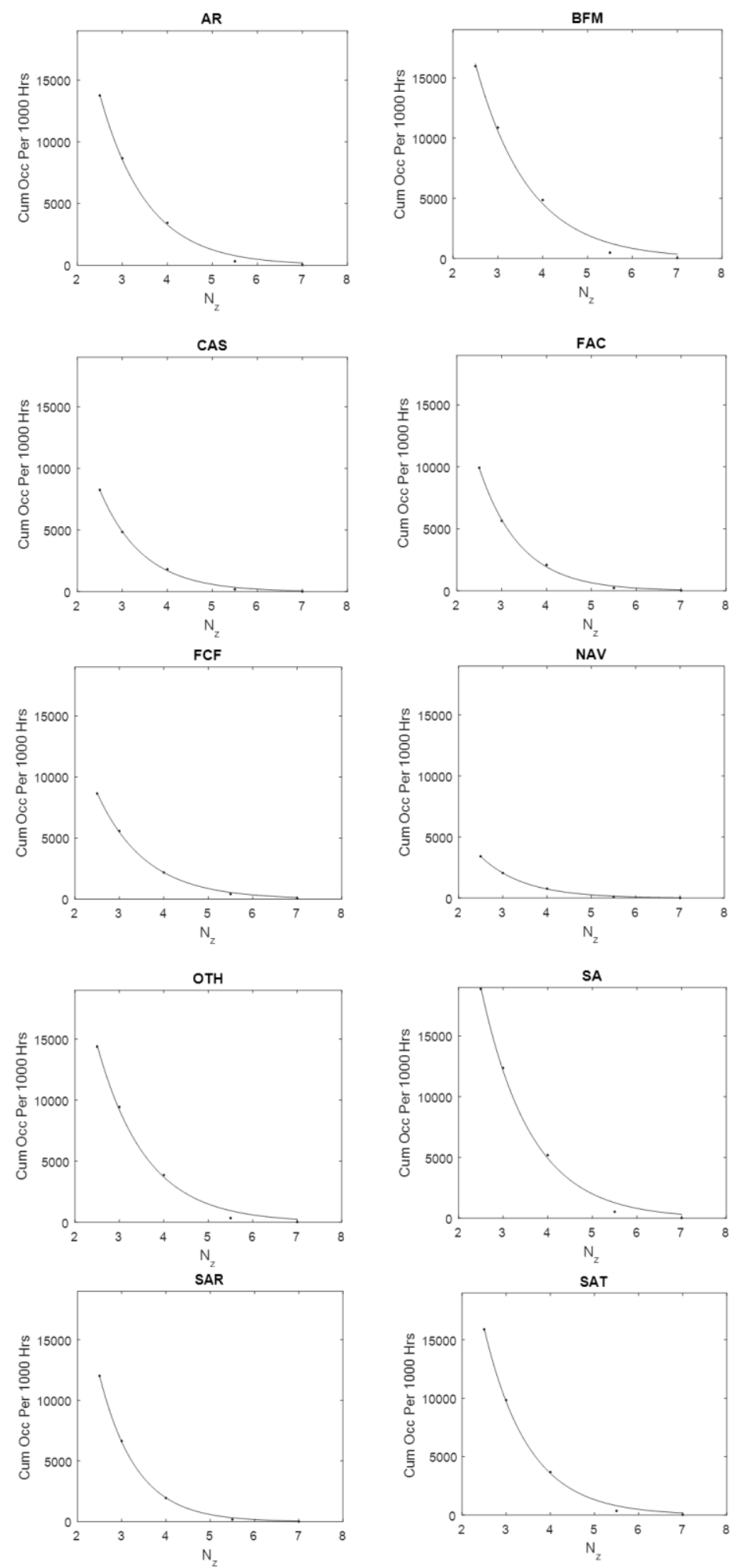

Fig. 6. Exponential fits for mission types.
Table 6

Coefficients for mission type exponential fits.

\begin{tabular}{crrrr}
\hline Mission & \multicolumn{1}{c}{$\mathbf{a}$} & \multicolumn{1}{c}{$\mathbf{b}$} & $\mathbf{R}^{\mathbf{2}}$ & \multicolumn{1}{c}{$\mathbf{R M S E}$} \\
\hline AR & $1.521 \mathrm{e}+05$ & -0.959 & 0.9980 & 306.2 \\
BFM & $1.34 \mathrm{e}+05$ & -0.8457 & 0.9950 & 562.2 \\
CAS & $1.137 \mathrm{e}+05$ & -1.049 & 0.9991 & 119.5 \\
FAC & $1.513 \mathrm{e}+05$ & -1.091 & 0.9992 & 138.8 \\
FCF & $8.743 \mathrm{e}+04$ & -0.9231 & 0.9993 & 108.4 \\
NAV & $4.351 \mathrm{e}+04$ & -1.017 & 0.9995 & 38.4 \\
OTH & $1.417 \mathrm{e}+05$ & -0.9115 & 0.9966 & 415.8 \\
SA & $1.797 \mathrm{e}+05$ & -0.8983 & 0.9970 & 514 \\
SAR & $2.461 \mathrm{e}+05$ & -1.207 & 0.9997 & 94.6 \\
SAT & $1.938 \mathrm{e}+05$ & -0.9982 & 0.9986 & 292.5 \\
\hline
\end{tabular}

3.2.1. Basic Fighter Maneuvers (BFM) and Surface Attack (SA) Missions Accrue the Most g-Counts

These two mission types have g-count occurrences per hour above the mean for each counting accelerometer subgroup. Tangibly, this means that these mission types have more g-transients and therefore contribute more to structural degradation [24]. Because the counting accelerometer system increments each time a normal load factor is surpassed, the aircraft is experiencing more departures from the normal acceleration of gravity in both the positive and negative directions. Since fatigue damage is caused by the accumulation of loading, BFM and SA missions contribute the most to aircraft lifetime usage. This assumes stores weight, stores location and aircraft fuel load for BFM and SA missions are similar to those of other mission types.

This result is sensible. BFM is an aggressive mission type because it simulates an air-to-air engagement. As the data show, pilots will utilize all regions of the flight envelope to gain an energy advantage against an opponent. SA missions are characteristically aggressive because the run-in and safe-escape phases of an engagement with a ground asset are designed to evade enemy ground fire.

\subsubsection{Close Air Support (CAS) and Navigation (NAV) Missions} Are the Least Damaging

CAS and NAV missions experience fewer g-transients compared to other mission types. These sorties spend more time at $1 \mathrm{~g}$. For CAS, this means more time orbiting an engagement area waiting for orders to engage an enemy position. Pilots flying CAS avoid excessive maneuvering and flight under elevated g-loads because of increased fuel burn for those actions and therefore decreased loiter time. NAV missions are generally flown over long distances where fuel consumption is closely monitored. Therefore, the likelihood for elevated g-loading is decreased.

\subsubsection{Aerial Refueling (AR) Missions Are Structurally Significant}

Pilot tendency to code a mission as AR is greatest for those missions whose primary purpose is practicing aerial refueling with a tanker aircraft. These missions may include multiple rejoins, boom connects/disconnects and simulated breakaways. Maneuvering near a tanker aircraft is usually in the middle of the flight envelope, near 1g. Simulated breakaways, where the refueling aircraft expeditiously separates from the tanker aircraft, 
often transit below $1 \mathrm{~g}$. This is shown in the data. AR missions account for a high number of $0.3 \mathrm{~g}$ counts.

\subsubsection{Functional Check Flight (FCF) Missions Represent the Most Extreme Flying}

FCF missions are required after major maintenance actions. These missions are designed to test the aircraft in all regions of the flight envelope to ensure the aircraft is capable of full functionality. Table 5 shows that FCF missions have the highest $7 \mathrm{~g}$ occurrences per flying hour. FCF missions also have the second highest occurrences per hour for the $0.3 \mathrm{~g}$ counter. This occurs because FCF missions are required to fly at the extremes of the flight envelope. BFM and SA accrue more counts than the mean, but FCF is also an important mission type for fleet managers because of its contribution to loading at the extremes of the loading spectrum.

Three sample mission types (SA, FCF and NAV) are shown in a spider plot as Fig. 7, which is a different representation of the data shown in Fig. 4. This plotting technique best shows the differences between an aggressive mission type (SA), a more docile mission type (NAV) and a mission type with skewed loading (FCF). The skewness best illustrated by the FCF data trace shows the abundance of $7 \mathrm{~g}$ counts accrued in FCF. The lines between each datum point were added for visual convenience and do not suggest continuous data.

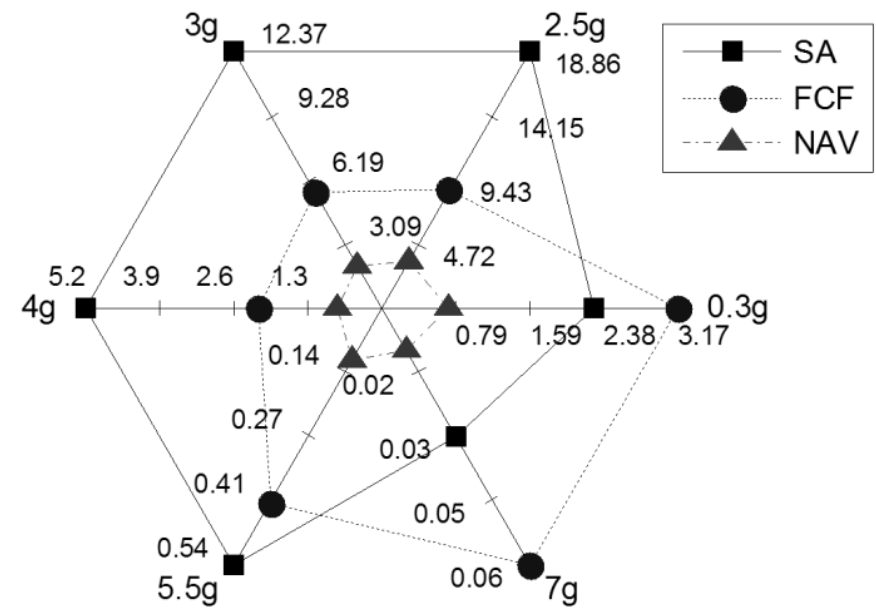

Fig. 7. Spider plot of normal load factor occurrences per flight hour.

\subsubsection{Relationship Between Aircraft Age and g-Counts}

Median counting accelerometer counts were tabulated for each age-ranked tail number to determine if aircraft age had an impact on an aircraft's g-count accumulation. The resulting linear trend equations are listed in Table 7, where $y$ represents gcount occurrences and $x$ represents aircraft age. Not enough nonzero data from the $5.5 \mathrm{~g}$ and $7 \mathrm{~g}$ counting accelerometers existed so their linear trend equations were omitted from Table 7 . The low coefficients of determination, measures of the total variance of the dependent variables that can be explained by the equations, are due to the large sample size. These equations show there to be no significant aircraft age effect on g-count accumulation rate. This implies that the reason for aircraft retirement must not be because older aircraft were flown harder in bygone days but might be because older aircraft have merely accumulated more structural loading through time.

Table 7

Counting accelerometer linear trend relating aircraft age.

\begin{tabular}{ccc}
$\begin{array}{c}\text { Counting } \\
\text { Accelerometer }\end{array}$ & $\begin{array}{c}\text { Linear Trend } \\
\text { Equation }\end{array}$ & $\mathbf{R}^{\mathbf{2}}$ \\
\hline $0.3 \mathrm{~g}$ & $\mathrm{y}=0.0009 \mathrm{x}+1.689$ & 0.0069 \\
$2.5 \mathrm{~g}$ & $\mathrm{y}=-0.0014 \mathrm{x}+20.937$ & 0.0003 \\
$3 \mathrm{~g}$ & $\mathrm{y}=-0.0019 \mathrm{x}+12.156$ & 0.0014 \\
$4 \mathrm{~g}$ & $\mathrm{y}=-0.0018 \mathrm{x}+4.5616$ & 0.0073 \\
\hline
\end{tabular}

\subsubsection{Relationship Between Flight Duration and g-Counts}

If older aircraft accumulate more structural loading through time, it must be shown that increased flight time correlates to increased loading. Fig. 8 illustrates the pattern comparing increasing flight duration to g-counts for one representative counting accelerometer $(5.5 \mathrm{~g})$. Only flight durations between 0.6 hours and 5.0 hours were plotted to best show the typical data and to exclude outliers. These exclusions reduced the number of samples compared to other plots in this section. As flight duration increases to the center of the distribution the tendency for higher g-counts increases. After the center, the tendency for higher g-counts decreases. The shape of the data shows that there is a flight duration effect. A longer flight duration gives a pilot more opportunity to maneuver the aircraft through the range of counting accelerometers. A density plot of the same data confirmed the relationship shown in Fig. 8. Excessive maneuvering increases g-counts but also consumes more fuel. During a sortie without aerial refueling, excessive maneuvering would lead to a shorter sortie duration. Therefore, sorties shown in the right-tail of the distribution represent two categories: sorties with minimal maneuvering to extend sortie duration and sorties where aerial refueling took place. These classes of missions are skewed towards long-distance flights, during which pilots refrain from excessive maneuvering. This result was verified through an interview with an A-10 test pilot [25]. For reference, the max endure label indicates the approximate maximum sortie duration without aerial refueling.

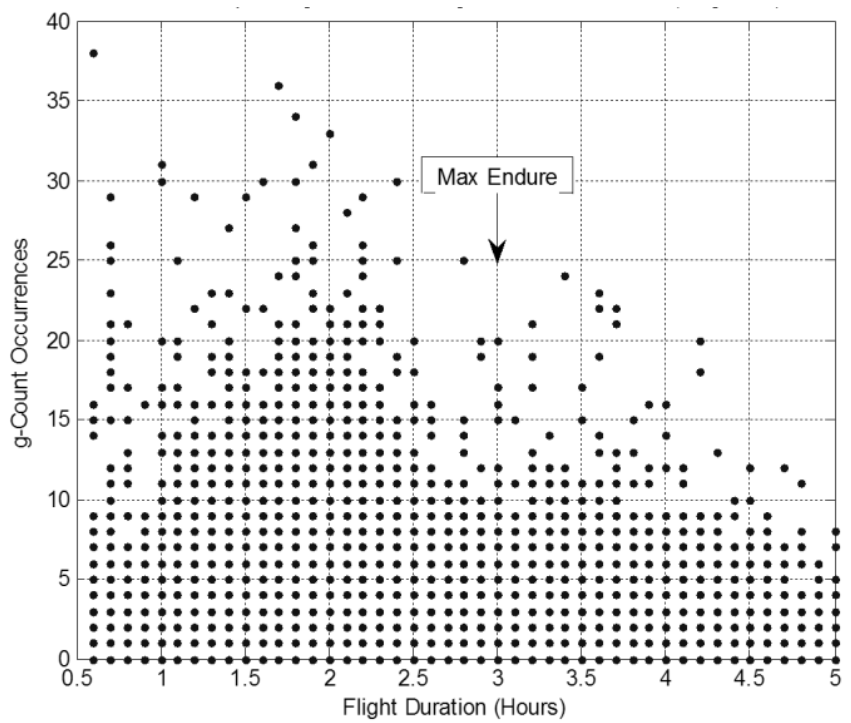

Fig. 8. Relationship of flight duration to g-count occurrences, $\mathrm{n}=265,680$. 
Assuming a stochastic makeup of flight assignments, it follows that aircraft with more flight hours, regardless of flight duration, would have accumulated more g-counts through time. Fig. 9 shows this relationship using data from the $4 \mathrm{~g}$ counting accelerometer for all 356 aircraft in the study. Aircraft with lower flight hours in the dataset tend to have shorter duration sorties, but higher g-counts (indicative of some mission types). Still, a natural scatter in the data confirms the stochastic nature of mission assignments across the fleet. A bivariate correlation of each of the counting accelerometer data revealed that all but the $7 \mathrm{~g}$ accelerometer had a positive correlation. The results, along with relationship and strength are contained in Table 8 [26].

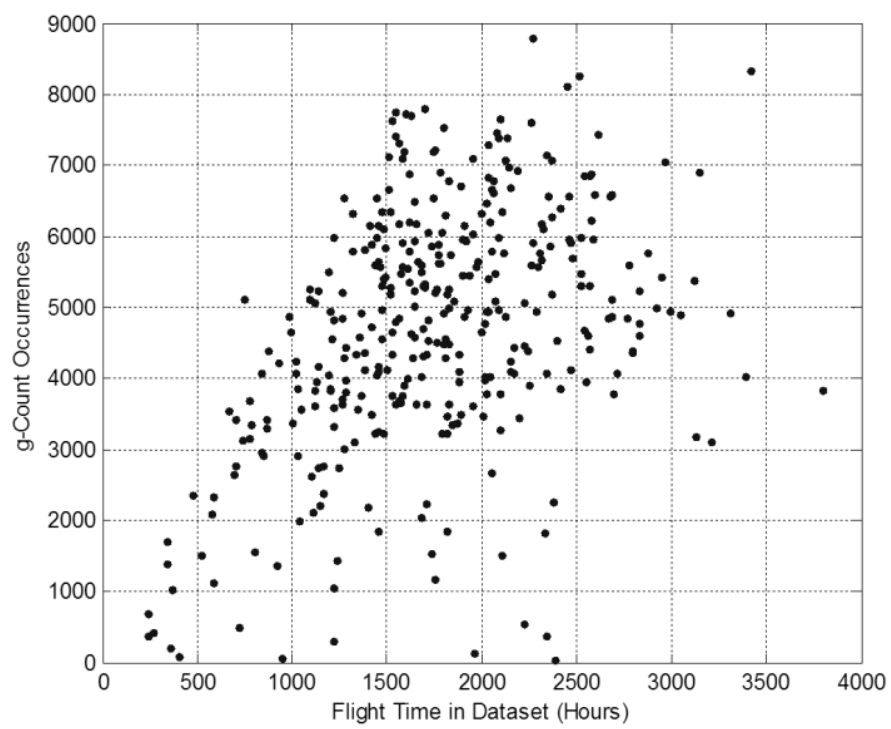

Fig. 9. Cumulative flight hours compared to g-counts for the $4 \mathrm{~g}$ counting accelerometer, $n=356$ aircraft.

Table 8

Bivariate correlation of g-counts to flight time in dataset.

\begin{tabular}{cccc}
\hline $\begin{array}{c}\text { Counting } \\
\text { Accelerometer }\end{array}$ & $\begin{array}{c}\text { Pearson } \\
\text { Corr. }(\mathbf{r})\end{array}$ & $\begin{array}{c}\text { Relationship - } \\
\text { Strength }\end{array}$ & Sig. \\
\hline $0.3 \mathrm{~g}$ & 0.289 & Pos $-\mathrm{Sm}$ & 0.000 \\
$2.5 \mathrm{~g}$ & 0.488 & Pos $-\mathrm{Med}$ & 0.000 \\
$3 \mathrm{~g}$ & 0.460 & Pos $-\mathrm{Med}$ & 0.000 \\
$4 \mathrm{~g}$ & 0.426 & Pos $-\mathrm{Med}$ & 0.000 \\
$5.5 \mathrm{~g}$ & 0.211 & Pos $-\mathrm{Sm}$ & 0.000 \\
$7 \mathrm{~g}$ & -0.100 & Neg $-\mathrm{Sm}$ & 0.058 \\
\hline
\end{tabular}

\subsection{Validation}

To verify the aforementioned data reduction and analysis methods, previous study data were evaluated for similarity. Benchmark A-10 cumulative occurrence data collected during a 6,000 flight hour usage profile in 1992 was provided by Grumman Aerospace Corporation [27]. The A-10 data from this 2016 study matched the profile data curvature from the 1992 collection showing a decrease in occurrence magnitude at the $7 \mathrm{~g}$ load factor (Fig. 10).

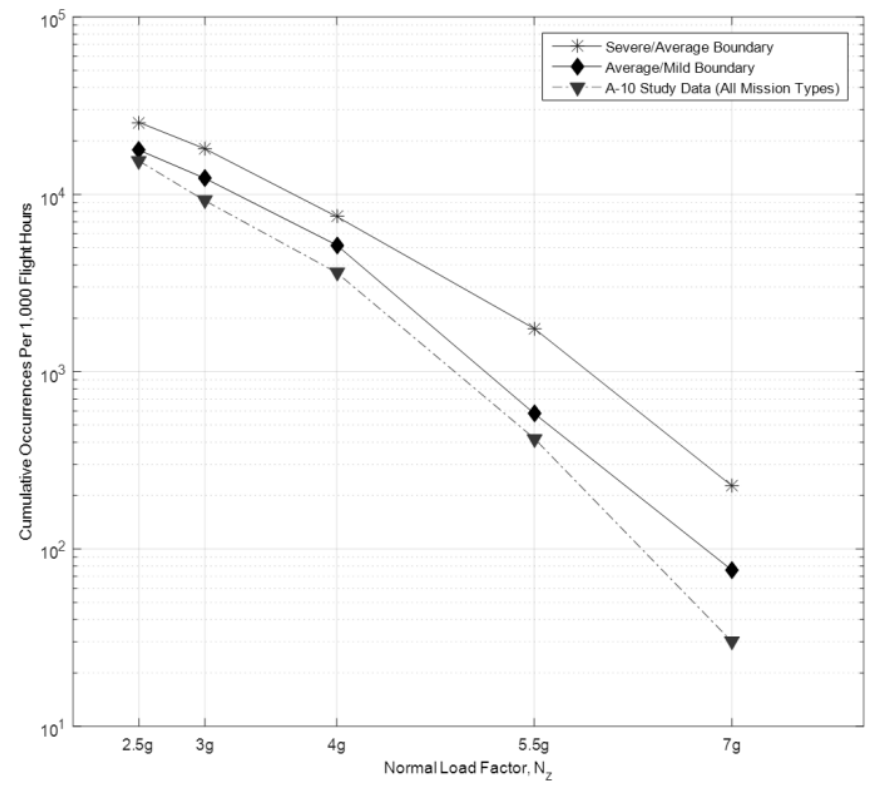

Fig. 10. 1992 Grumman A-10 severity spectrum compared to 2016 study data.

Other unclassified counting accelerometer data exist for a variety of aircraft but the work done by De Fiore, Leikach and Bohannon and Kaniss provided the most relevant military attack aircraft data [28], [29], [30], [31]. Navy Blue Angels A-4F data recorded in 1975 had a usable data retention rate of $73.68 \%$, which was comparable to this study's $68.36 \%$ retention rate [29]. The B-1B capture rate has been as high as $75 \%$ and as low as $60 \%$ [22]. De Fiore's analysis showed that increasing $\mathrm{N}_{\mathrm{z}}$ increases the coefficient of variation in the data, similar to what was found in this study's data [28]. Also, De Fiore found differences in loadings by mission type, a primary hypothesis of this study [15]. He concluded that air-to-ground missions were the most severe and navigation missions were nearly the least severe. However, De Jonge's Weibull distribution fits possessed a lower coefficient of determination than this study's exponential distribution fits. The reason for the small difference could be from the difference in sample size or operational reporting techniques. It is sensible to fit an exponential function to data collected in an incremental fashion.

Counting accelerometer bin frequencies in other aircraft studies mirrored the data in this study. Fig. 11 shows data from the Royal Australian Navy's A-4G Skyhawk (16 aircraft representing 15,502 flight hours, 1962-1977) and the U.S. Navy's A-7A Corsair II (194 aircraft representing 197,869 flight hours, 1932-1974) alongside A-10 data [31], [28]. The exponential fit equation is shown in Equation 4 where $x$ is defined as the normal load factor. This exponential fit appears to be a poor fit because of the logarithmic ordinate, but the $\mathrm{R}^{2}$ is 0.9967 . 


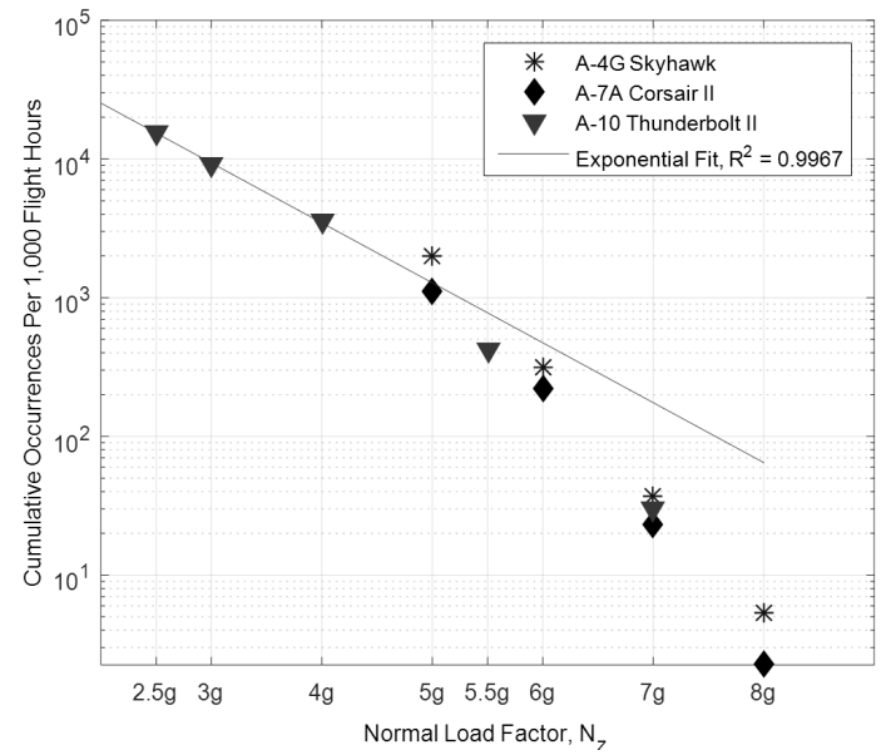

Fig. 11. Comparison of counting accelerometer data for multiple attack aircraft.

$$
f(x)=1.85 \times 10^{5} e^{-0.9949 x}
$$

The comparison studies showed evidence that model variations (A-7A versus A-7B, for example) led to usage differences and within model mission assignments (lead versus chase, for example) led to usage differences. In the case of the latter, the chase aircraft is subjected to greater loading than the lead aircraft. Unfortunately, there is no designator or derived parameter in this study's dataset that defines lead versus chase aircraft roles.

Looking at mission design series designations and data compiled by the United States Navy, the USAF and Fokker aircraft, it is clear that each aircraft type experiences different loading patterns. Attack aircraft usage spectra fall toward the middle of aircraft usage for the types identified in Fig. 12. Fighter aircraft and flight demonstration aircraft accrue more damaging flight hours while bomber, cargo and passenger aircraft accrue less damaging flight hours. This validation step shows that the macroscopic discussion of aircraft type matters just as mission types matter within an aircraft type. Fig. 12 was constructed using representative aircraft possessing counting accelerometer technology from each type category. All data were previously published [22], [32], [28].

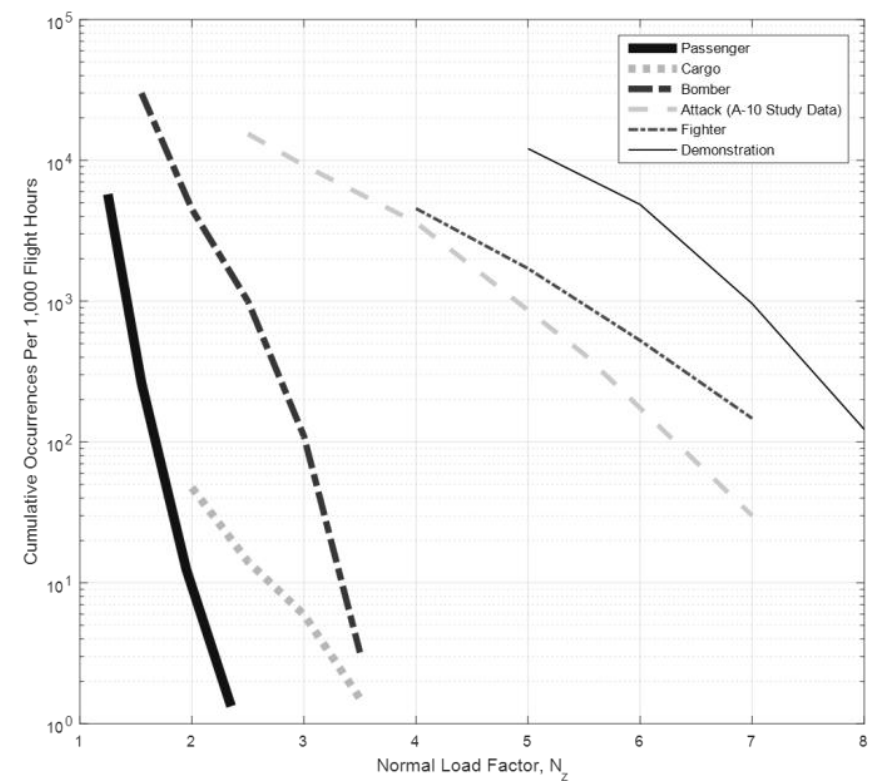

Fig. 12. Comparison of counting accelerometer data for aircraft types.

Lastly, the finding that flights longer than some peak lead to fewer g-counts is supported by De Jonge and Hol's analysis of Fokker F27 and F28 commercial aircraft hourly damage calculations [32]. They found a decreasing trend in loading accumulation per flight hour because the percentage of flight time consisting of high loading takeoffs and landings is less for a long flight [32].

\section{Impact}

The correlation between mission type and structural loading is a bridge between structural health monitoring data collection and implementation of those findings. This result is directly useful for military aircraft fleet operators and will impact the assignment of aircraft to varying mission roles. Fleet managers faced with the retirement decision may opt to reassign aircraft to less structurally damaging mission types thereby prolonging fleet viability.

Some nations and military services do this as standard practice, as discussed by Simpson [33]. The dialogue about extending service lives of aircraft now has a study that shows how closer mission type management can realize fleet lifetime extension. Military aircraft outside of the attack genre and commercial aircraft fleets can benefit from these results through use of the presented assessment strategy with their fleet-specific input data.

\section{Conclusions}

This study has answered two hypotheses relating to the correlation of mission type to aircraft loading using case study data from the A-10 attack aircraft. The A-10 was chosen because it is wholly representative of attack aircraft worldwide. The A-10 dataset matched attack aircraft from the United States Navy and the Royal Australian Navy, proving these findings are not limited to USAF aircraft alone. Further studies would be needed to confirm the applicability of the conclusions of this 
study for other aircraft types and for those in the commercial sector.

The first hypothesis posited that the type of mission impacts the loading pattern experienced by an attack aircraft. Data showed that there is a marked difference in g-counts for aircraft flying dissimilar mission types. This result was seen for each of the 10 mission types analyzed in the A-10 dataset. The differences were found to be statistically significant. Exponential decay models showed differences in the mission types and form the underlying equations for future optimization methods. Fleet managers can use these equations for fleet planning and mission allocation strategies.

The second hypothesis stated that some mission types account for greater loading damage accumulation. This was shown to be true. For the analyzed dataset, Basic Fighter Maneuvers and Surface Attack accrued the greatest elevated gcounts while Close Air Support and Navigation accrued the least elevated g-counts. ASIP managers interested in prolonging aircraft lifetime can use these results to prioritize mission types that accrue the least number of elevated g-counts. For example, an aircraft's lifetime could in practice be prolonged by flying fewer Basic Fighter Maneuvers or Surface Attack and more Close Air Support or Navigation.

These conclusions are vital for future research in this area. Because mission types are a distinct variable for aircraft loading history, there will exist an optimization for aircraft mission utilization. Accordingly, because military aircraft bases are often mission-specific, basing optimization will result in a change to fleet-wide loading accumulation.

The plethora of available counting accelerometer data is underutilized by researchers because they have focused on more modern structural health monitoring techniques. There is a lot to be gained from legacy data because it shows usage patterns over a much longer lifespan than more recent monitoring technologies. This paper has shown the intrinsic value in using existing data to show correlations in aircraft usage, which leads to potential for structural lifetime extension.

\section{Disclaimer}

The views expressed in this paper are those of the authors and do not reflect the official policy or position of the United States Air Force, Department of Defense, or the United States Government. This research was funded by the United States Air Force. The authors declare no conflict of interest.

\section{References}

[1] SAB, Sustaining Air Force Aging Aircraft Into the 21st Century, S.A. Board, Editor. 2011: Washington D.C.

[2] Johns, J.D., Strategies to Sustain an Aging Fleet. 2013, DTIC Document.

[3] DoD, Annual Aviation Inventory and Funding Plan Fiscal Years 2016-2045, D.o. Defense, Editor. 2015: Washington D.C.

[4] DoD, MIL-STD-1530C: Aircraft Structural Integrity Program (ASIP). 2005: Washington D.C. p. 42.
USAF, Air Force Policy Directive 63-10: Aircraft Structural Integrity. 1997, Department of the Air Force: Washington D.C.

[6] Kinzig, W.C., USAF Strategy for Aging Aircraft Subsystem Research and Development. 2003, DTIC Document.

[7] Kudva, J.N., A.J. Lockyer, and C.B. Van Way, Structural health monitoring of aircraft components. AGARD Lecture Series, 1996: p. 9-9.

[8] NRC, Aging of U.S. Air Force Aircraft. 1997, National Academy Press: Washington D.C. p. 119.

[9] Yechout, T.R., et al., Introduction to aircraft flight mechanics: performance, static stability, dynamic stability, classical feedback control, and state-space foundations. Second ed. AIAA Education Series. 2014, Reston, Virginia: American Institute of Aeronautics and Astronautics, Inc. xvii, 700 pages.

[10] Molent, L. and B. Aktepe, Review of fatigue monitoring of agile military aircraft. Fatigue \& Fracture of Engineering Materials \& Structures, 2000. 23(9): p. 767-785.

[11] DoD, MIL-A-22145C(AS): Accelerometer Group, Counting (Rescinded: 1999). 1992: Washington D.C. p. 27.

[12] Taylor, J., Design and use of counting accelerometers. 1954: HM Stationery Office.

[13] Gray, T., Individual aircraft tracking methods for fighter aircraft utilizing counting accelerometer data. 1978, DTIC Document.

[14] Lambert, J., The use of Counting Accelerometer data in fatigue life predictions for aircraft flying in complex roles. Fatigue Life Prediction for Aircraft Structures and Materials, 1973.

[15] De Jonge, J., Load experience variability of fighter aircraft. 1989.

[16] Albert, A.P., et al., A Systems Engineering Approach to Integrated Structural Health Monitoring for Aging Aircraft. 2006, DTIC Document.

[17] Connor, D., et al. Coast Guard Efforts to Deal with Aging Aircraft. in NASA Conference Publication. 1999. NASA.

[18] Maley, S., J. Plets, and N. Phan. US Navy Roadmap to Structural Health and Usage Monitoring-The Present and Future. in Annual Forum Proceedings - American Helicopter Society. 2007. American Helicopter Society, Inc.

[19] Staszewski, W., C. Boller, and G.R. Tomlinson, Health monitoring of aerospace structures: smart sensor technologies and signal processing. 2004: John Wiley $\&$ Sons.

[20] Boyd, P., Ageing Aircraft Management Plan, A. Government, Editor. 2012: Canberra, Australia. p. 20.

[21] De Jonge, J., Fatigue Load Monitoring. 1978, Advisory Group for Aerospace Research \& Development. p. 146.

[22] Denyer, A.G. Service life monitoring of the B- $1 B$ and the impact on flight operations and structural maintenance. in 7th RTO Meeting Proceedings on Exploitation of Structural Loads/Health Data for Reduced Life Cycle Costs, Brussels, Belgium. 1998. 
[23] Holpp, J. and M. Landy, The development of fatigue/crack growth analysis loading spectra. 1976, DTIC Document.

[24] Curran, R., et al., A Value Operations Methodology (VOM) approach to usage driven maintenance. Journal of Aerospace Operations, 2012. 1(4): p. 401-419.

[25] Haywas, L., Discussion On A-10 Counting Accelerometer System, J. Newcamp, Editor. Personal Communication. Tucson, Arizona. p. 1.

[26] Cohen, J., Statistical Power Analysis for the Behavioral Sciences. 2 ed. 1988, Hillsdale, NJ: Erlbaum.

[27] Bierds, W., A-10A Individual Aircraft Fracture Tracking Analysis Using 2nd 6000 Hour Database. 1992, Grumman Aerospace Corporation: Bethpage, N.Y.p. 422.

[28] De Fiore, T.A., Statistical Review of Counting Accelerometer Data for Navy and Marine Fleet Aircraft from 1 January 1962 to 1 July 1973. 1973, DTIC Document.

[29] Leikach, K. and G. Bohannon, A-4F Blue Angel Flight Usage Data 1974-1975. 1976, DTIC Document.

[30] Leikach, K. and G. Bohannon, A-4F Blue Angel Flight Usage Data-1976. 1977, DTIC Document.

[31] Kaniss, A.M., Statistical Review of Counting Accelerometer Data for Navy and Marine Fleet Aircraft from 1 Jan 1962 to 30 Jun 1977. 1977, DTIC Document.

[32] De Jonge, J. and P. Hol, Variation in load experience: A re-analysis of Fokker F27 and Foker F28 operational acceleration data. 1996, Nationaal Lucht-en Ruimtevaartlaboratorium.

[33] Simpson, D., Canadian CF-18 Structural Life Management Program. Aging Aircraft Combat FleetsLong Term Applications, 1996. 
Jeffrey Newcamp is a Major in the United States

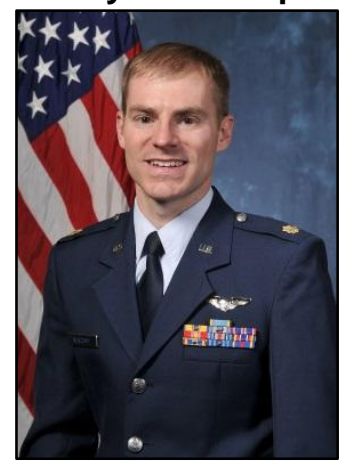

Air Force and a PhD candidate at the Delft University of Technology, in Delft, Netherlands. His research foci include aging aircraft, aircraft operations and aircraft safety. Prior to his current work, Major Newcamp was an Assistant Professor of Aeronautics and Systems Engineering at the United States Air Force Academy and has been a flight test engineer for the F-35 Joint Strike Fighter. Major Newcamp holds three masters degrees, is a FAA certified private pilot and has flight time in 27 military and civilian aircraft types.

Dr. W.J.C. Verhagen is the Assistant Professor of

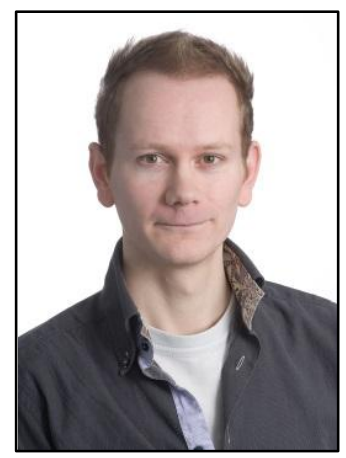
Maintenance Operations in the Air Transport and Operations section at the Delft University of Technology. His research focuses on aircraft maintenance operations, with specific attention to development of knowledgebased maintenance systems and optimization models to improve the efficiency of aircraft maintenance planning and execution.

Professor Ricky Curran is Full Professor at Delft

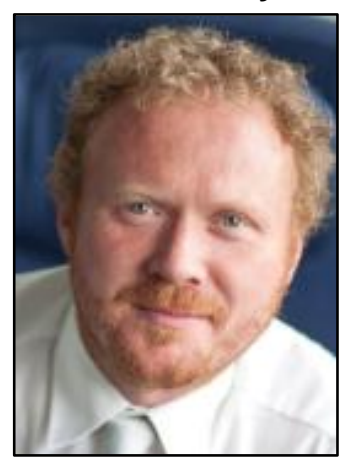
University of Technology and head of the Air Transport and Operations section. He is an Associate Fellow of the American Institute of Aeronautics and Astronautics (AIAA). He is also a member of the Economics Technical Committee, the Value Driven Design Programme Committee and the Progress in Aerospace Sciences Editorial Board. $\mathrm{He}$ is also President of the International Society for Productivity Enhancement (ISPE). Among various editorial positions he is also the Editor in Chief of the Journal of Aerospace Operations and General Chair and founder of the Air Transport and Operations Symposium (ATOS). 